\title{
Analisis Faktor Konsumen Pria Membeli Jasa Perawatan Wajah di Larissa Aesthetic Center Semarang
}

\author{
Vany Dwi Hapsari, M. Widyanto
}

email: markus@unika.ac.id

Fakultas Ekonomi dan Bisnis Unika Soegijapranata

\begin{abstract}
This research was conducted to know the reasons male consumers buy face treatment. Survey was conducted and sampling by purposive sampling toward 105 respondents and collecting data by questionnaires. The results of factor analysis by SPSS software showed 6 factors identified which influenced male consumer tend buying face treatment in Larissa Aesthetic Center Semarang. First factor was expert doctor and price promotion (variance 29.4\%). Second factor was accessability (variance $14.2 \%$ ). Third factor was service quality (variance 11.3\%). Fourth factor was membership card (variance 6.2\%). Fifth factor was quality and parking space (variance 5.4\%). And sixth factor was service and consumer testimony (variance 4.9\%).
\end{abstract}

Keywords: consumer behaviour, factor analysis, service quality, price promotion, testimony

\section{PENDAHULUAN}

Perkembangan bisnis skin care saat ini telah berkembang sangat pesat, khususnya pada bisnis skin care di Semarang. Perawatan kulit wajah telah menjadi kebutuhan bagi sebagian masyarakat khususnya para wanita. Namun saat ini banyak kita jumpai kaum pria juga membeli jasa perawatan di skin care mulai dari membersihkan wajah dengan scrub, facial, serta menggunakan lotion wajah hingga tubuh.

Di Indonesia sendiri Larissa skin care telah berkembang pesat, setidaknya ada lebih dari lima jenis skin care dengan berbagai cabang yang tersebar di seluruh Indonesia. Larissa Aesthetic Center tidak hanya menawarkan jasa perawatan untuk wanita saja, namun menyediakan jasa perawatan untuk pria. Upaya membuka cabang di beberapa kota besar di Indonesia bertujuan untuk memenangkan persaingan dan memantapkan pilihan pelanggan. Beberapa skin care tersebut antara lain London Beauty Center (LBC), Natasha Skin Care, Erha Clinic, Larissa Aeshetic Center dan Ella Skin Care. 
Perilaku konsumen merupakan tindakan yang langsung terlibat dalam mendapatkan, mengkonsumsi, dan menghabiskan produk dan jasa, termasuk proses keputusan yang mendahului dan menyusuli tindakan ini (Engel \& all, 1994:3). Biasanya para pria melakukan perawatan dan membeli beberapa produk pendukung yang ditawarkan seperti sun-block wajah, krim malam dan pagi, lotion jerawat untuk mengecilkan jerawat, dan lotion tubuh untuk melembabkan dan mencerahkan kulit. Maka sangat penting bagi perusahaan mengetahui karakteristik konsumennya.

Salah satu klinik kecantikan yang cukup ternama di Semarang adalah Larissa Aesthetic Center. Berawal pada tanggal 11 Juni 1984, R. Ngt. Poetji Lirnawati mendirikan Larissa Beauty Salon yang berawal dari sebuah keinginan memberikan pelayanan di bidang perawatan kulit dan rambut yang aman bagi konsumen. Konsep yang dikembangkan oleh Larissa Aesthetic Center adalah perawatan kulit dan rambut yang menggunakan bahan- bahan alami seperti buah, sayuran, umbi, beras "back to nature" (www.larissa.co.id). Larissa Aesthetic Center merupakan salon pertama yang mengembangkan perawatan kecantikan yang berorientasi pada konsep back to nature dengan menggunakan bahan-bahan alami yang diproduksi sendiri. Saat ini, Larissa sudah memiliki cabang yang tersebar di beberapa kota seperti Solo, Semarang, Salatiga, Klaten, Purwokerto,Tegal, Surabaya, Malang dan Kediri (www.larissa.co.id).

Tabel 1

Harga Perawatan di Skin Care

\begin{tabular}{|l|l|}
\hline Skin Care & Harga Perawatan \\
\hline Natasha Skin Care & $75.000-299.000$ \\
\hline Larissa Aesthetic Center & $45.000-350.000$ \\
\hline Erha Clinic & $50.000-1.000 .000$ \\
\hline London Beauty Center & $70.000-300.000$ \\
\hline Ella Skin Care & $50.000-200.000$ \\
\hline
\end{tabular}

Sumber : Survei Peneliti ke lokasi Skin Care di Semarang (2016)

Dari tabel harga dapat mempengaruhi konsumen untuk mencoba perawatan di Skin Care yang diharapkan, harga sering kali menjadi tolok ukur yang 
dihubungkan dengan manfaat yang dirasakan atas suatu barang dan jasa. Konsumen akan lebih menilai harga itu murah atau mahal jika mereka mendaptkan hasil yang diinginkan.

Tabel 2

Perkiraan Jumlah Pengunjung Skin Care

\begin{tabular}{|l|c|c|}
\hline skin care & $\begin{array}{l}\text { Jumlah pengunjung } \\
\text { wanita/ hari }\end{array}$ & $\begin{array}{l}\text { Jumlah pengunjung } \\
\text { pria/ hari }\end{array}$ \\
\hline Natsha Skin Care & 250 & 105 \\
\hline $\begin{array}{l}\text { Larissa Aesthetic } \\
\text { Center }\end{array}$ & 280 & 100 \\
\hline Erha Clinic Beauty & 195 & 85 \\
\hline $\begin{array}{l}\text { London Center } \\
\text { Ella Skin Care }\end{array}$ & 155 & 80 \\
\hline
\end{tabular}

Sumber : Data Primer Skin Care di Semarang 2016.

Durasi perawatan yang ditawarkan antara pria dan wanita sama yaitu 1,5 hingga 2 jam tergantung permasalahan kulit. Larissa juga menyediakan perawatan rambut dan badan untuk pria, namun jarang diminati, biasanya lebih berminat untuk melakukan perawatan wajah seperti facial wajah. Semua perawatan di Larissa Aesthetic Center ini didukung oleh alat-alat modern sehingga konsumen akan lebih percaya jika melakukan perawatan disana. Selain melakukan perawatan wajah para pria ini juga sering membeli produk pencerah kulit karena menurut mereka kulit yang cerah akan menjadi daya tarik tersendiri bagi konsumen dan orang lain yang melihatnya. Berdasarkan uraian diatas, maka penulis memutuskan melakukan penelitian dengan judul “Analisis Faktor Konsumen Pria Dalam Membeli Jasa Perawatan Kulit Wajah di Larissa Aestehetic Center Semarang”

\section{Rumusan Masalah}

Penampilan yang bersih dan terawat akan mendapatkan respek dari lingkungannya dan tentu saja untuk menarik perhatian wanita, selain itu tuntutan pekerjaan juga dapat berpengaruh untuk menunjang penampilan agar terlihat lebih menarik. Sehubungan dengan perilaku konsumen sebagai kegiatan-kegiatan 
individu yang secara langsung terlibat dalam mendapatkan dan mempergunakan barang-barang dan jasa-jasa,termasuk didalamnya proses pengambilan keputusan pada persiapan dan penentuan kegiatan-kegiatan tersebut.

Berdasarkan uraian diatas rumusan masalah dalam penelitian ini yaitu : Faktor -faktor apa sajakah yang mempengaruhi konsumen pria untuk membeli jasa perawatan kulit wajah di Larissa Aesthetic Center Semarang ? Faktor apa yang paling dominan konsumen pria membeli jasa perawatan wajah di Larissa Aesthetic Center Semarang.

\section{LANDASAN TEORI}

\section{Perilaku Konsumen}

Melalui pengetahuan tentang perilaku konsumen, perusahaan akan mengetahui hal-hal yang baru dalam mengembangkan usahanya dengan melihat kebutuhan dan keinginan konsumen yang belum terpenuhi. Dari pengetahuan ini akan memudahkan perusahaan dalam mempengaruhi konsumen untuk mau memilih dan membeli produk yang ditawarkan perusahaan. Perilaku konsumen sebagai tindakan yang langsung terlibat dalam mendapatkan, mengkonsumsi, dan menghabiskan produk dan jasa, termasuk proses keputusan yang mendahului dan menyusuli tindakan ini. Pengertian ini dapat dirancang dari beberapa perspektif, yaitu : perspektif pengaruh konsumen, perspektif menyeluruh, dan perspektif antar budaya (Engel \& all, 1994:3).

\section{Pengertian Gaya Hidup}

Gaya hidup merupakan pola dimana seseorang hidup dan menghabiskan waktu atau uang (Engel \& all, 1994: 383). Sedangkan gaya hidup menurut adalah pola hidup seseorang yang tergambarkan pada aktivities, interests, dan opinions (AIO) orang tersebut (Kotler \& Amstrong ,2001: 210). Seiring dengan berkembangnya jaman, masyarakat juga mengalami perubahan gaya hidup, berbagai macam kemudahan yang ada saat ini mendorong masyarakat untuk berpola hidup praktis. Salah satunya adalah masyarakat mulai menyukai 
perawatan untuk memaksimalkan penampilan agar terlihat lebih menarik. Perawatan wajah dan tubuh sangat diperlukan saat ini karena manusia menganggap dirinya akan diterima di masyarakat apabila penampilan mereka menarik dan dikagumi oleh orang lain.

\section{Kepuasan dan Loyalitas Pelanggan}

Kepuasan pelanggan adalah tingkatan dimana anggapan kinerja (perceived perfomance) produk akan sesuai dengan harapan seorang pembeli. Bila kinerja produk jauh lebih rendah dibandingkan harapan pelanggan, pembelinya tidak puas. Bila kinerja sesuai dengan harapan atau melebihi harapan, pembelinya merasa puas atau merasa amat gembira (Kotler \& Amstrong, 2001:10). Oliver dalam Kotler \& Keller (Rosi Nur Afifah, 2014) mendefinisikan loyalitas sebagai komitmen yang dipegang secara mendalam untuk membeli atau mendukung kembali produk atau jasa yang disukai di masa depan meski pengaruh situasi dan usaha pemasaran berpotensi menyebabkan pelanggan beralih. Loyalitas pelanggan bisa muncul karena adanya kepuasan konsumen sebagai akibat dari layanan yang memenuhi harapan konsumen sehingga tidak beralih ke produk lain. Mempertahankn konsumen merupakan bagian penting dalam menciptakan loyalitas konsumen, karena mempertahankan konsumen bukanlah hal yang mudah, perusahaan harus menciptakan nilai bagi konsumennya.

\section{Kualitas Produk}

Kualitas produk adalah kemampuan suatu produk untuk melakukan fungsi-fungsinya;kemampuan itu meliputi daya tahan, kehandalan, ketelitian yang di hasilkan, kemudahan dioperasikan dan diperbaiki, dan atribut lain yang berharga pada produk secara keseluruhan (Kottler dan Amstrong, 2001:347). Kualitas produk juga harus dapat ditentukan dengan cara konsumen memandang produk tersebut. Menurut Cannon, dkk ( Rosi Nur Afifah, 2014 ) dari sudut pandang pemasaran, kualitas produk berarti kemampuan produk untuk memuaskan kebutuhan atau keinginan pelanggan. Menurut Boyd,dkk (Rosi Nur Afifah, 2014), untuk menentukan dimensi kualitas produk dapat melalui delapan dimensi sebagai berikut : Kinerja, Tampilan, Keandalan, Konformasi, Daya Tahan, 
Kemampulayanan, Estetika, dan Persepsi Mutu. Suatu produk dapat dikatakan memiliki kualitas yang baik bila produk tersebut mencakup dimensi tersebut.

\section{Kecantikan dan Keindahan}

Menurut Levine \& Smolak (kompasiana.com, 2011), mengatakan bahwa kecantikan yang menjadi daya tarik untuk menggapai eksistensi tersebut menyebabkan suatu permasalahan yang menyebabkan suatu rasa ketidakpuasan mereka terhadap keadaan fisik yang mereka miliki dengan kondisi fisik ideal yang mereka dambakan. Banyak konsumen rela mengeluarkan kocek yang cukup dalam untuk mendapatkan kulit yang mereka inginkan. Klinik - klinik kecantikan yang bisa mencerahkan kulit wajah ( Didin Dwi Kartikasari,2014). Dari semua masalah yang dikeluhkan konsumen, masalah kulit yang sering dihadapi khusunya kulit wajah, kulit wajah adalah bagian terpenting untuk dirawat karena lingkungan akan memperhatikan wajah terlebih dahulu untuk menilai seseorang. Menurut Widyo Nugroho dan Achmad Muchji (1996), keindahan dikatakan dapat bersifat universal, maksudnya keindahan tidak terikat oleh pendapat perseorangan, waktu, tempat kedaerahan ataupun selera mode yang sedang berkembang, hal itu disebabkan karena keindahan akan dapat terlihat atau dirasakan ketika telah dikaitkan dengan sesuatu yang berwujud, seperti benda atau suatu pemandangan.

\section{Marketing Mix}

Bauran pemasaran atau marketing mix menurut Kottler dan Amstrong (Amanda,2016) bauran pemasaran merupakan sekumpulan alat pemasaran taktis terkendali yang dipadukan perusahaan untuk menghasilkan respon yang diinginkan dipasar sasaran. Mengelompokkan dimana marketing mix terdiri semua hal yang dilakukan sebuah perusahaan untuk mempengaruhi permintaan produk, terdapat empat kelompok yang disebut 4P, dalam pemasaran produk, harga, tempat, promosi. Sedangkan untuk usaha jasa menurut Alma dan Buchari (2004), bauran pemasaran atau marketing mix berupa 4P yaitu, produk, price,place and promotion, serta dilengkapi dengan 3P yaitu people, physical evidence dan process. 


\section{Definisi Operasional}

Definisi operasional variabel dalam penelitian ini sebagai berikut:

- Variasi produk. Larissa Aesthetic Center menyediakan berbagai macam varian produk dari masker wajah ( Greentea, beras, bengkoang dll), lalu untuk perawatan wajah dari facial biasa yang menggunakan beras untuk kulit normal, sampai facial messo acne untuk kulit yang berjerawat.

- Kemasan Menarik. Pengemasan untuk produk seperti tempat yang mudah dibawa kemana mana, lalu warna tidak terlalu mencolok yang disediakan Larissa Aesthetic Center tergolong cukup rapi dan warnanya menarik sehingga konsumen percaya akan keamanan produk.

- Kualitas Produk. Produk yang ditawarkan sudah mencantumkan label standar keamanan.

- Harga Terjangkau. Harga yang ditawarkan cukup terjangkau, harga ini cenderung relatif dan dapat dijangkau oleh konsumen menengah.

- Pembayaran mudah. Transaksi pembayaran dapat menggunakan cash, debit serta kartu kredit.

- Potongan Harga. Potongan harga yang diberikan oleh perusahaan diharapkan untuk meningkatkan penjualan.

- Tempat strategis. Tempat yang strategis akan menambah nilai plus untuk pelanggan karena pelanggan tidak dengan susah mencari tempat perawatan dan konsumen

- Lokasi ditengah kota. Lokasi Larissa Aesthetic Center ini berada ditengah kota sehingga konsumen mudah mengenali Skin Care ini.

- Ketersediaan lahan parkir. Ketersediaan lahan parkir mempengaruhi kenyaman konsumen pada saat ingin memarkirkan kendaraan mereka.

- Kenyamanan ruang tunggu. Konsumen akan merasa nyaman jika ruang tunggu nyaman dan bersih sehingga konsumen betah untuk menunggu giliran antri.

- Pemberian hadiah. Pemberian hadiah kepada konsumen loyal akan menambah citra merek untuk perusahaan tersebut.

- Alat modern. Persepsi konsumen jika membeli jasa perawatan wajah dengan alat modern, mereka akan lebih puas dan lebih percaya dengan pelayanan yang ada.

- Pelayanan ramah. Konsumen yang mendapat pelayanan yang baik akan merasa dihargai dengan begitu mereka senantiasa akan kembali lagi untuk melakukan treatment.

- Beauty therapist yang profesional. Beauty therapist memegang peran penting dalam hal ini, karena perusahaan menetapkan pegawai yang direkrut adalah lulusan terbaik dan profesional, berpenampilan menarik, teliti, cekatan, dan yang memiliki komitmen dalam melayani konsumen.

- Dokter Spesialis kulit. Skin Care menyediakan dokter spesialis kulit untuk menunjang fasilitas perusahaan bahwa perusahaan benar - benar berkualitas dalam melayani konsumen agar konsumen dapat berkonsultasi mengenai masalah kulit wajah mereka dengan saran dokter langsung.

- Free biaya konsultasi dokter. Perusahaan menyediakan layanan bebas biaya 
konsultasi dokter yang akan menarik perhatian calon konsumen yang akan membeli jasa perawatan di Larissa Aesthetic Center, sehingga konsumen tidak lagi mempermasalahkan biaya dan takut untuk melakukan konsultasi dengan dokter lagi.

- Pelayanan cepat. Pelayanan treatment yang dilakukan tidak berbelit-belit meskipun antri panjang namun konsumen tidak terlalu lama menunggu.

- Member card. Perusahaan menyediakan member card untuk menunjukan bahwa konsumen loyal terhadap perusahaan..

- Banyak testimoni. Persepsi konsumen jika banyak yang cocok melakukan perawatan di Larisa Aesthetic Center mereka akan tertarik untuk mencobanya.

- Referensi teman. Konsumen pria memutuskan untuk melakukan perawatan karena di beritahu teman saat menunggu atau pernah melakukan perawatan di tempat tersebut.

- Mempercantik diri. Sebagian pria memang membeli jasa perawatan untuk mempercantik diri karena mereka menganggap seperti perempuan.

\section{Kerangka Pikir}

Dalam penelitian ini terdapat 21 variabel yang akan dilakukan analisis faktor konsumen pria dalam melakukan perawatan kulit wajah di Larissa Aesthetic Center di Semarang. Berikut ini adalah kerangka pikir

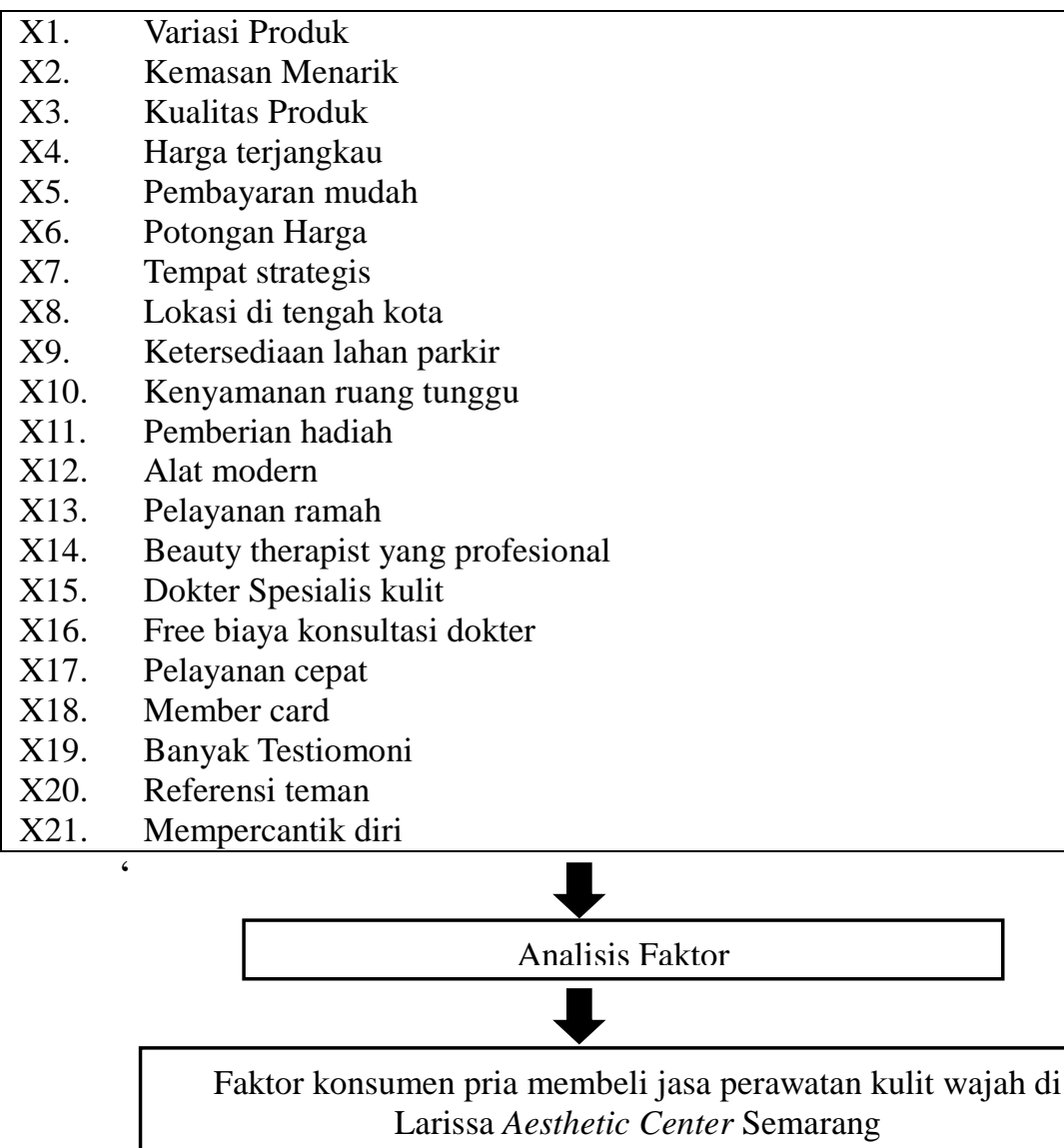

Faktor konsumen pria membeli jasa perawatan kulit wajah di Larissa Aesthetic Center Semarang 


\section{METODE PENELITIAN}

\section{Obyek, Populasi dan Sampling Penelitian}

Objek penelitian ini adalah Larissa Aesthetic Center Semarang. Populasi adalah wilayah generalisasi yang terdiri atas obyek atau subyek yang mempunyai kualitas dan karakteristik tertentu yang ditetapkan oleh peneliti untuk dipelajari dan kemudian ditarik kesimpulannya (Sugiyono, 2010: 117). Populasi dalam penelitian ini adalah konsumen pria yang pernah membeli jasa perawatan wajah di Larissa Aesthetic Center Semarang. Sampel menurut Sugiyono (2010: 118) merupakan bagian dari jumlah dan karakteristik yang dimiliki oleh populasi tersebut. Untuk itu, sampel yang diambil dari populasi harus betul-betul representatif (mewakili). Sampel dalam penelitian ini adalah konsumen pria yang berkunjung di Larissa Aesthetic Center Semarang. Konsumen dalam penelitian ini adalah konsumen pria yang berusia 18-25 tahun.

Dalam pengambilan sampel, peneliti menggunakan metode non-probability sampling sebab dalam pemberian sampel tidak memberi peluang atau kesempatan sama bagi setiap unsur atau anggota populasi untuk dipilih menjadi sampel. Sedangkan, teknik pengambilan sampel dalam penelitian ini adalah teknik purposive sampling, yaitu teknik pengambilan sampel yang memiliki tujuan atau karakteristik tertentu. Oleh karena itu, ditentukanlah kriteria untuk menjadi responden dalam penelitian ini. Berikut adalah kriterianya:

a. Usia 18-25 tahun

b. Pernah membeli jasa perawatan wajah di Larissa Aesthetic Center Semarang minimal satu kali.

Penentuan jumlah sampel responden didasarkan pada pernyataan Supranto, yang menyatakan bahwa ukuran sampel yang baik dapat ditentukan dengan cara, jumlah pertanyaan (variabel) dalam kuesioner dikalikan lima (5). Dalam penelitian ini, peneliti mendapatkan 21 variabel, maka dikalikan 5 hasilnya adalah 105. Sehingga jumlah responden dalam penelitian ini adalah 105 orang. 


\section{Sumber dan Teknik Pengumpulan Data}

Data yang digunakan adalah data primer. Data primer adalah data yang dikumpulkan dan diolah sendiri oleh suatu organisasi atau perorangan langsung dari objeknya (Singgih \& Tjiptono, 2001:59). Data yang digunakan dalam penelitian ini diperoleh melalui teknik kuesioner. Kuesioner merupakan teknik pengumpulan data yang dilakukan dengan cara memberi seperangkat pertanyaan atau pernyataan tertulis kepada responden untuk dijawabnya (Sugiyono, 2010: 199). Peneliti dalam penelitian ini membagi kuesioner kepada responden.

\section{Uji Validitas}

Uji validitas menurut Azwar (2000:5) sejauhmana ketepatan dan kecermatan suatu alat ukur dalam melakukan fungsi ukurnya.Dalam pengujian validitas, peneliti menggunakan alat bantu program komputer yaitu SPSS for Windows 22.

Tabel 3

Hasil Uji Validitas

\begin{tabular}{|l|l|l|l|}
\hline Variabel & r Hitung & r Tabel & Keterangan \\
\hline X1 & 0,326 & 0,1918 & Valid \\
\hline X2 & 0,353 & 0,1918 & Valid \\
\hline X3 & 0,309 & 0,1918 & Valid \\
\hline X4 & 0,246 & 0,1918 & Valid \\
\hline X5 & 0,205 & 0,1918 & Valid \\
\hline X6 & 0,763 & 0,1918 & Valid \\
\hline X7 & 0,261 & 0,1918 & Valid \\
\hline X8 & 0,352 & 0,1918 & Valid \\
\hline X9 & 0,364 & 0,1918 & Valid \\
\hline X10 & 0,259 & 0,1918 & Valid \\
\hline X11 & 0,790 & 0,1918 & Valid \\
\hline X12 & 0,691 & 0,1918 & Valid \\
\hline X13 & 0,505 & 0,1918 & Valid \\
\hline X14 & 0,733 & 0,1918 & Valid \\
\hline X15 & 0,744 & 0,1918 & Valid \\
\hline X16 & 0,753 & 0,1918 & Valid \\
\hline X17 & 0,479 & 0,1918 & Valid \\
\hline X18 & 0,447 & 0,1918 & Valid \\
\hline X19 & 0,241 & 0,1918 & Valid \\
\hline X20 & 0,244 & 0,1918 & Valid \\
\hline X21 & 0,230 & 0,1918 & Valid \\
\hline & & & \\
\hline
\end{tabular}


Berdasarkan uji validitas diatas, dengan ketentuan Df $=$ Jumlah responden $2(\mathrm{Df}=105-2=103)$ dan alpha 5\% maka digunakan $\mathrm{r}$ Tabel $103=$ 0,1918. Keseluruhan dalam penelitian ini dinyatakan valid.

\section{Uji Reliabilitas}

Reliabilitas sebenarnya adalah hasil pengukuran dapat dipercaya hanya apabila dalam beberapa kali pelaksanaan pengukuran terhadap kelompok subjek yang sama diperoleh hasil yang relative sama, selama aspek yang diukur dalam diri subjek memang belum berubah ( Azwar, 2000:4). Uji reliabilitas dalam penelitian ini juga menggunakan alat bantu program komputer yaitu SPSS for Windows 22 dengan menggunakan model Cronbach Alpha. Untuk mengambil suatu keputusan reliabilitas, suatu kuesioner dianggap reliabel jika nilai Cronbach Alpha lebih besar dari 0,60.

\section{Tabel 4}

Hasil Uji Reliabilitas

Reliability Statistics

\begin{tabular}{|r|r|}
\hline Cronbach's Alpha & \multicolumn{1}{|c|}{ N of Items } \\
\hline .731 & 21 \\
\hline
\end{tabular}

Sumber : Data Primer diolah tahun 2016

Berdasarkan hasil pengujian diatas dapat dilihat bahwa nilai Cronbach’s Alpha adalah 0,731 . Sehingga variabel-variabel dalam penelitian ini dinyatakan reliable karena nila Cronbach’s Alpha lebih dari 0,60.

\section{Metode Analisis Data}

\section{Analisis Statistik Deskriptif}

Analisis statistik deskriptif adalah alat analisis yang digunakan untuk menganalisis data dengan melakukan deskripsi atau menggambarkan data-data yang telah terkumpul tanpa bermaksud untuk membuat kesimpulan yang berlaku untuk umum (Sugiyono,2010:207). Menurut Sugiyono (2010: 207), statistik deskriptif adalah statistik yang digunakan untuk menganalisis data dengan cara mendeskripsikan atau menggambarkan data yang telah terkumpul sebagaimana adanya tanpa bermaksud membuat kesimpulan yang berlaku untuk umum atau generalisasi. 
Penelitian ini menggunakan sejumlah pertanyaan dan pernyataan dengan 5 skala yang menunjukkan setuju atau tidak setuju terhadap statement tersebut.

a. Skor 1 untuk Sangat Tidak Setuju (STS)

b. Skor 2 untuk Tidak Setuju (TS)

c. Skor 3 untuk Netral (N)

d. Skor 4 untuk Setuju (S)

e. Skor 5 untuk Sangat Setuju (SS)

Tabel 5

Kategori Rentang Skala

\begin{tabular}{|c|c|}
\hline Rentang Skala & Kategori \\
\hline $1,0-1,8$ & Sangat Tidak Setuju \\
$1,8-2,6$ & Tidak Setuju \\
$2,6-3,4$ & Netral \\
$3,4-4,2$ & Setuju \\
$4,2-5,0$ & Sangat Setuju \\
\hline
\end{tabular}

\section{Analisis Faktor}

Analisis faktor pada prinsipnya digunakan untuk mereduksi data, yaitu proses untuk meringkas sejumlah variabel menjadi lebih sedikit dan menamakannya sebagai faktor (Santoso \& Tjiptono, 2001: 248). Secara garis besar, berikut adalah tahapan pada analisis faktor:

- Memilih variabel yang layak dimasukkan dalam analisis faktor. Oleh karena analisis faktor berupaya mengelompokkan sejumlah variabel, maka seharusnya ada korelasi yang cukup kuat di antara variabel, sehingga akan terjadi pengelompokkan. Jika sebuah variabel atau lebih berkorelasi lemah dengan variabel lainnya, maka variabel tersebut akan dikeluarkan dari analisis faktor.

- Setelah sejumlah variabel terpilih, maka variabel tersebut diekstraksi hingga menjadi satu atau beberapa faktor. Beberapa metode pencarian faktor yang populer adalah Principal Component dan Maximum Likehood.

- Faktor yang terbentuk biasanya kurang menggambarkan perbedaan diantara faktor-faktor yang ada. Hal tersebut akan mengganggu analisis, karena justru sebuah faktor harus berbeda secara nyata dengan faktor yang lain. Untuk itu, jika isi faktor masih diragukan, dapat dilakukan proses rotasi untuk memperjelas 
apakah faktor yang terbentuk sudah secara signifikan berbeda dengan faktor lain.

- Setelah faktor benar-benar sudah terbentuk, maka proses dilanjutkan dengan menamakan faktor yang ada. Kemudian, beberapa langkah akhir juga perlu dilakukan, yaitu validasi hasil faktor.

\section{HASIL PENELITIAN DAN PEMBAHASAN}

\section{Deskripsi Responden}

Gambaran responden berdasarkan usia dalam penelitian ini diketahui menunjukkan usia responden pria dalam membeli jasa perawatan wajah di Larissa Aesthetic Center Semarang. Dapat diketahui bahwa dari 105 responden yang pernah membeli jasa perawatan wajah dilihat dari usia 18-20 tahun yaitu 19 responden atau $18,10 \%$ dari total responden adalah pelajar. Sisanya 86 responden atau 81,90\% usia 20-25 tahun adalah pegawai menjadi kategori usia yang mendominasi dalam penelitian ini.

Berdasarkan hasil pengolahan data dapat diketahui bahwa responden dengan status sebagai pelajar SMA berjumlah 5 responden atau sebesar 4,76\%, mahasiswa berjumlah 40 responden atau 38,09\%, pegawai berjumlah 60 responden atau sebesar 57,15\%, Dengan demikian dapat disimpulkan dalam penelitian ini bahwa konsumen pria dengan status pegawai menjadi mayoritas membeli jasa perawatan wajah di Larissa Aesthetic Center Semarang para pria membutuhkan perawatan wajah guna menjaga penampilan agar tetap maksimal.

\section{Identitas Responden Berdasarkan Kebutuhan Perawatan wajah yang Dibeli}

Tabel berikut ini berisikan data kebutuhan responden membeli jasa perawatan wajah. 
Tabel 6

Kebutuhan Membeli Jasa Perwatan Wajah

\begin{tabular}{|c|c|c|}
\hline Kebutuhan Perawatan & Jumlah & Presentase \\
\hline Membersihkan Komedo & 87 & 18,40 \\
\hline Mencerahkan Kulit & 12 & 2,53 \\
\hline Penasaran melakukan perawatan & 31 & 6,55 \\
\hline Tuntutan Pekerjaan & 89 & 18,82 \\
\hline Mengencangkan Kulit & 20 & 4,22 \\
\hline Menghilangkan Jerawat & 66 & 13,95 \\
\hline Wajah tampak Glowing & 8 & 1,69 \\
\hline Menghilangkan flek hitam & 3 & 0,63 \\
\hline Menunjang penampilan & 33 & 6,97 \\
\hline Merelaksasikan pikiran & 22 & 4,65 \\
\hline Tampil Beda & 11 & 2,32 \\
\hline Menarik Perhatian wanita & 27 & 5,67 \\
\hline Wajah tampak lebih putih & 7 & 1,47 \\
\hline Menambah kepercayaan diri & 13 & 2,74 \\
\hline Menghaluskan kulit & 44 & 9,30 \\
\hline TOTAL & $\mathbf{4 7 3}$ & 100 \\
\hline
\end{tabular}

Sumber: Data primer yang diolah peneliti tahun 2016

Dari tabel di atas, dapat diketahui bahwa kebutuhan pria melakukan perawatan wajah yang paling banyak diminati karena tuntutan pekerjaan. Hal ini dapat dibuktikan bahwa dari 105 responden 89 responden atau 18,82\% pernah membeli jasa perawatan wajah karena tuntutan pekerjaan. Posisi kedua terbanyak adalah membersihkan komedo yaitu sebanyak 87 responden atau 18,40\%, kemudian menghilangkan jerawat juga menjadi kebutuhan pria membeli jasa perawatan wajah sebanyak 66 responden atau 13,95\% dan untuk menunjang penampilan sebanyak 33 responden atau 6,97\%.

\section{Gambaran Responden Berdasarkan Frekuensi Perwatan Wajah}

Gambaran responden berdasarkan frekuensi perawatan wajah dalam penelitian ini dapat diketahui pada tabel sebagai berikut : 
Tabel 7

Gambaran Responden Berdasarkan Frekuensi Perawatan

\begin{tabular}{|l|c|c|}
\hline Frekuensi Perawatan & Jumlah & Persentase \\
\hline$<1$ bulan yang lalu & 34 & 32,39 \\
1 - 3 bulan yang lalu & 66 & 62,85 \\
$>3$ bulan yang lalu & 5 & 4,76 \\
\hline Jumlah & 105 & 100,00 \\
\hline
\end{tabular}

Sumber: data primer yang diolah tahun 2016

Dapat diketahui pada tabel bahwa konsumen pria membeli jasa perawatan wajah di Larissa Aesthetic Center dalam penelitian ini dari 105 responden, 62,85\% dari total responden atau 66 responden telah melakukan pembelian jasa perawatan wajah di Larissa Aesthetic Center selama 1 hingga 3 bulan yang lalu karena konsumen pria ini mengikuti anjuran dokter untuk kembali perawatan minimal dua minggu hingga satu bulan sekali tergantung masalah kulit wajah masing-masing konsumen.

\section{Tabulasi silang Usia dan Frekuensi Perawatan}

Dari tabel tabulasi silang dapat diketahui bahwa usia 20-25 tahun sering membeli jasa perawatan wajah dalam kurun waktu 1-3 bulan yang lalu sebanyak 86 responden. Hal ini menunjukkan bahwa mereka membutuhkan perawatan dan mengikuti saran yang diberikan dokter agar perawatan yang dilakukan mendapat hasil yang lebih maksimal.

Tabel 8

Tabulasi Silang Usia dan Frekuensi Perawatan Wajah

\begin{tabular}{|c|c|c|c|c|c|}
\hline & & \multicolumn{3}{|c|}{ PERAWATAN } & \multirow[b]{2}{*}{ Total } \\
\hline & & $\begin{array}{l}<1 \text { bulan } \\
\text { yang lalu }\end{array}$ & $\begin{array}{l}1-3 \text { bulan } \\
\text { yang lalu }\end{array}$ & $\begin{array}{l}>3 \text { bulan } \\
\text { yang lalu }\end{array}$ & \\
\hline \multirow{2}{*}{ USIA } & $18-20$ & 1 & 17 & 1 & 19 \\
\hline & $20-25$ & 33 & 49 & 4 & 86 \\
\hline Total & & 34 & 66 & 5 & 105 \\
\hline
\end{tabular}

Sumber: data primer yang diolah ahun 2016 


\section{Analisis Statistik Deskriptif}

Tabel berikut berisi total skor dan rata-rata skor jawaban dari 105 responden terhadap 21 variabel dalam penelitian ini :

Tabel 9

Statistik Deskriptif

\begin{tabular}{|c|c|c|c|c|c|c|c|c|c|}
\hline \multirow[t]{2}{*}{ No } & \multirow[t]{2}{*}{ Variabel } & \multicolumn{5}{|c|}{ Frekuensi jawaban } & \multirow{2}{*}{$\begin{array}{l}\text { Total } \\
\text { Skor }\end{array}$} & \multirow{2}{*}{ Rata-rata } & \multirow{2}{*}{ kategori } \\
\hline & & STS & TS & $\mathrm{N}$ & $\mathrm{S}$ & SS & & & \\
\hline \multirow[t]{2}{*}{1} & Variasi layanan & 0 & 0 & 5 & 80 & 20 & & & \\
\hline & Total & 0 & 0 & 15 & 320 & 100 & 435 & 4,15 & Setuju \\
\hline \multirow[t]{2}{*}{2} & Kemasan Produk & 1 & 14 & 17 & 69 & 4 & & & \\
\hline & Total & 1 & 28 & 51 & 276 & 20 & 376 & 3,6 & Setuju \\
\hline \multirow[t]{2}{*}{3} & Kualitas Produk & 0 & 0 & 4 & 96 & 5 & & & \\
\hline & Total & 0 & 0 & 12 & 384 & 25 & 421 & 4 & Setuju \\
\hline \multirow[t]{2}{*}{4} & Harga & 0 & 0 & 2 & 75 & 28 & & & \\
\hline & Total & 0 & 0 & 6 & 300 & 140 & 446 & 4,24 & $\begin{array}{l}\text { Sangat } \\
\text { Setuju }\end{array}$ \\
\hline \multirow[t]{2}{*}{5} & Kemudahan Pembayaran & 0 & 1 & 10 & 87 & 7 & & & \\
\hline & Total & 0 & 2 & 30 & 348 & 35 & 415 & 4 & Setuju \\
\hline \multirow[t]{2}{*}{6} & Potongan Harga & 11 & 11 & 16 & 64 & 3 & & & \\
\hline & Total & 11 & 22 & 48 & 256 & 15 & 352 & 3,4 & Setuju \\
\hline \multirow[t]{2}{*}{7} & Tempat strategis & 0 & 4 & 8 & 88 & 5 & & & \\
\hline & Total & 0 & 8 & 24 & 325 & 25 & 382 & 3,65 & Setuju \\
\hline \multirow[t]{2}{*}{8} & Lokasi & 0 & 1 & 13 & 82 & 9 & & & \\
\hline & Total & 0 & 2 & 39 & 356 & 45 & 442 & 4,20 & Setuju \\
\hline \multirow[t]{2}{*}{9} & Parkir & 23 & 54 & 9 & 18 & 1 & & & \\
\hline & Total & 23 & 108 & 27 & 72 & 5 & 235 & 2,25 & $\begin{array}{l}\text { Tidak } \\
\text { Setuju }\end{array}$ \\
\hline \multirow[t]{2}{*}{10} & Ruang Tunggu & 0 & 3 & 7 & 70 & 25 & & & \\
\hline & Total & 0 & 6 & 21 & 280 & 125 & 432 & 4,12 & Setuju \\
\hline \multirow[t]{2}{*}{11} & Pemberian Hadiah & 14 & 10 & 17 & 62 & 2 & & & \\
\hline & Total & 14 & 20 & 51 & 248 & 10 & 343 & 3,26 & Netral \\
\hline \multirow[t]{2}{*}{12} & Alat Modern & 9 & 1 & 4 & 81 & 10 & & & \\
\hline & Total & 9 & 2 & 12 & 324 & 50 & 397 & 3,8 & Setuju \\
\hline \multirow[t]{2}{*}{13} & Beauty Therapis & 5 & 12 & 4 & 73 & 11 & & & \\
\hline & Total & 5 & 24 & 12 & 292 & 55 & 493 & 4,7 & $\begin{array}{l}\text { Sangat } \\
\text { Setuju }\end{array}$ \\
\hline \multirow[t]{2}{*}{14} & Dokter Spesialis Kulit & 5 & 11 & 5 & 69 & 15 & & & \\
\hline & Total & 5 & 22 & 15 & 276 & 75 & 393 & 3,75 & Setuju \\
\hline \multirow[t]{2}{*}{15} & Biaya Konsultasi & 16 & 1 & 6 & 58 & 24 & & & \\
\hline & Total & 16 & 2 & 18 & 232 & 120 & 388 & 3,7 & Setuju \\
\hline
\end{tabular}




\begin{tabular}{|c|c|c|c|c|c|c|c|c|c|}
\hline \multirow[t]{2}{*}{ No } & \multirow[t]{2}{*}{ Variabel } & \multicolumn{5}{|c|}{ Frekuensi jawaban } & \multirow{2}{*}{$\begin{array}{l}\text { Total } \\
\text { Skor }\end{array}$} & \multirow{2}{*}{ Rata-rata } & \multirow{2}{*}{ kategori } \\
\hline & & STS & TS & $\mathrm{N}$ & $\mathrm{S}$ & SS & & & \\
\hline \multirow[t]{2}{*}{16} & Kecepatan Layanan & 0 & 5 & 10 & 85 & 5 & & & \\
\hline & Total & 0 & 10 & 30 & 340 & 25 & 405 & 3,85 & Setuju \\
\hline \multirow[t]{2}{*}{17} & Member Card & 0 & 8 & 9 & 86 & 2 & & & \\
\hline & Total & 0 & 16 & 27 & 344 & 10 & 397 & 3,8 & Setuju \\
\hline \multirow[t]{2}{*}{18} & Testimoni & 0 & 6 & 4 & 83 & 12 & & & \\
\hline & Total & 0 & 12 & 12 & 332 & 60 & 416 & 3,96 & Setuju \\
\hline \multirow[t]{2}{*}{19} & Referensi Teman & 1 & 3 & 4 & 91 & 6 & & & \\
\hline & Total & 1 & 6 & 12 & 273 & 30 & 322 & 3,06 & Netral \\
\hline \multirow[t]{2}{*}{20} & Pelayanan Ramah & 0 & 2 & 9 & 88 & 6 & & & \\
\hline & Total & 0 & 4 & 27 & 352 & 30 & 413 & 3,95 & Setuju \\
\hline \multirow[t]{2}{*}{21} & Mempercantik diri & 0 & 6 & 22 & 62 & 15 & & & \\
\hline & Total & 0 & 12 & 66 & 248 & 75 & 401 & 3,8 & Setuju \\
\hline
\end{tabular}

Sumber: Data primer yang diolah peneliti tahun 2016

\section{Analisis Faktor}

Dalam pengolahan data untuk melakukan analisis faktor, dalam penelitian ini peneliti menggunakan program SPSS versi 22.

\section{KMO and Bartlett's Test}

Berikut adalah Tabel yang berisikan output spss KMO and Bartlett's Test:

Tabel 10

KMO and Bartlett's Test

Kaiser-Meyer-Olkin Measure of Sampling

Adequacy.

Bartlett's Test of

Sphericity
Approx. Chi-Square

Df

Sig.
1387.554

210 .000

Sumber : Data Primer yang diolah peneliti tahun 2016

Dari hasil pengolahan data menggunakan SPSS22 menunjukkan nilai KMO (Kaiser Meyer-Oikin) sebesar 0,742, sehingga sampel yang diambil memenuhi syarat serta nilai Bartlet’s Test of Sphericity sebesar 1387,554 dengan signifikansi 
sebesar 0,000, yang berarti mendukung kesimpulan bahwa variabel-variabel dalam penelitian ini dapat diproses lebih lanjut.

\section{Anti Image Correlation}

Tabel berikut ini menunjukkan besaran nilai MSA masing-masing variabel. Nilai MSA masing-masing variabel didapatkan dengan melihat tabel anti image matrics pada bagian bawah yaitu pada bagian anti image correlation. Sejumlah angka yang membentuk garis diagonal dan memiliki tanda 'a' menandakan nilai atau besaran MSA sebuah variabel.

Tabel 11

Anti Image Correlation

\begin{tabular}{|l|c|}
\hline Variabel & Nilai MSA \\
\hline Variasi layanan & 0,779 \\
\hline Kemasannya menarik & 0,748 \\
\hline Kualitas produknya & 0,424 \\
\hline transaksi mudah & 0,679 \\
\hline Potongan harga & 0,839 \\
\hline Tempat Strategis & 0,506 \\
\hline lokasi tengah kota & 0,573 \\
\hline Lahan parkir luas & 0,638 \\
\hline Ruang tunggu nyaman & 0,573 \\
\hline Memberikan hadiah & 0,911 \\
\hline menggunakan alat modern & 0,692 \\
\hline Pelayanan ramah & 0,637 \\
\hline Beauty therapis professional & 0,846 \\
\hline Dokter spesialis kulit & 0,864 \\
\hline Konsultasi dokter & 0,855 \\
\hline Pelayanan cepat & 0,571 \\
\hline Menyediakan member card & 0,542 \\
\hline Banyak testimony & 0,659 \\
\hline Referensi teman & 0,784 \\
\hline Mempercantik diri & 0,725 \\
\hline
\end{tabular}

Sumber : Data Primer yang diolah peneliti tahun 2016 
Berdasarkan data dalam tabel di atas, ada 21 variabel yang terdapat dalam penelitian ini yang dapat diproses lebih lanjut dalam analisis faktor. Angka MSA 21 variabel yang ada dalam penelitian ini memiliki nilai di atas 0,5. Variabel memberikan hadiah menjadi variabel dengan nilai MSA tertinggi $(0,911)$ sedangkan variabel kualitas produk menjadi variabel dengan nilai MSA terendah $(0,424)$.

\section{Communalities}

Berikut ini adalah tabel yang berisikan hasil output SPSS communalities:

Tabel 12

Communalities

\begin{tabular}{|l|r|r|}
\hline Variabel Penelitian & \multicolumn{1}{|c|}{ Initial } & Extraction \\
\hline Variasi layanan & 1 & 0.774 \\
\hline Kemasannya menarik & 1 & 0.578 \\
\hline Kualitas produknya & 1 & 0.786 \\
\hline Harga terjangkau & 1 & 0.624 \\
\hline Pembayaran mudah & 1 & 0.679 \\
\hline Potongan harga & 1 & 0.076 \\
\hline Tempatnya Strategis & 1 & 0.067 \\
\hline Lokasi ditengah kota & 1 & 0.793 \\
\hline Lahan parkir luas & 1 & 0.633 \\
\hline Ruang tunggu nyaman & 1 & 0.534 \\
\hline Memberikan hadiah & 1 & 0.794 \\
\hline menggunakan alat modern & 1 & 0.728 \\
\hline Pelayanan ramah & 1 & 0.648 \\
\hline beauty therapis professional & 1 & 0.893 \\
\hline Dokter spesialis kulit & 1 & 0.911 \\
\hline Konsultasi dokter & 1 & 0.915 \\
\hline Pelayanan cepat & 1 & 0.723 \\
\hline Menyediakan member card & 1 & 0.771 \\
\hline Banyak testimony & 1 & 0.456 \\
\hline Referensi teman & 1 & 0.534 \\
\hline Mempercantik diri & 1 & \\
\hline
\end{tabular}

Sumber: Data primer yang diolah peneliti tahun 2016 
Nilai communalities menunjukkan kuat maupun lemahnya hubungan variabel terhadap faktor yang terbentuk. Semakin tinggi nilai communalities maka akan semakin kuat hubungan variabel tersebut dengan faktor yang terbentuk, sebaliknya apabila nilai communalities kecil maka hubungan variabel tersebut dengan faktor yang terbentuk akan semakin lemah. Berdasarkan tabel di atas, variabel konsultasi dokter menjadi variabel dengan nilai communalities tertinggi yaitu (0,915). Angka ini menunjukkan sekitar 91,5\% varians dari variabel konsultasi dokter dapat dijelaskan oleh faktor-faktor yang terbentuk. Sedangkan variabel tempatnya strategis memiliki nilai communalities terendah yaitu 0,67 yang berarti 6,7\% varians dari variabel tersebut dapat dijelaskan oleh faktor yang akan terbentuk.

\section{Total Variance Explained}

Berikut ini adalah Tabel yang berisikan ouput SPSS total variance explained:

Tabel 13

Total Variance Explained

\begin{tabular}{|c|c|c|c|c|c|c|c|c|c|}
\hline \multicolumn{10}{|c|}{ Total Variance Explained } \\
\hline \multirow{2}{*}{ Component } & \multicolumn{3}{|c|}{ Initial Eigenvalues } & \multicolumn{3}{|c|}{$\begin{array}{c}\text { Extraction Sums of Squared } \\
\text { Loadings }\end{array}$} & \multicolumn{3}{|c|}{$\begin{array}{c}\text { Rotation Sums of Squared } \\
\text { Loadings }\end{array}$} \\
\hline & Total & $\begin{array}{c}\% \text { of } \\
\text { Variance } \\
\end{array}$ & $\begin{array}{c}\text { Cumulative } \\
\%\end{array}$ & Total & \begin{tabular}{|c|}
$\%$ of \\
Variance \\
\end{tabular} & $\begin{array}{c}\text { Cumulative } \\
\%\end{array}$ & Total & \begin{tabular}{|c|}
$\%$ of \\
Variance \\
\end{tabular} & $\begin{array}{c}\text { Cumulative } \\
\%\end{array}$ \\
\hline 1 & 6.175 & 29.404 & 29.404 & 6.175 & 29.404 & 29.404 & 5.744 & 27.352 & 27.352 \\
\hline 2 & 2.989 & 14.232 & 43.637 & 2.989 & 14.232 & 43.637 & 2.707 & 12.888 & 40.240 \\
\hline 3 & 2.375 & 11.312 & 54.948 & 2.375 & 11.312 & 54.948 & 2.101 & 10.006 & 50.246 \\
\hline 4 & 1.307 & 6.225 & 61.173 & 1.307 & 6.225 & 61.173 & 1.582 & 7.533 & 57.779 \\
\hline 5 & 1.134 & 5.400 & 66.573 & 1.134 & 5.400 & 66.573 & 1.483 & 7.063 & 64.842 \\
\hline 6 & 1.040 & 4.953 & 71.526 & 1.040 & 4.953 & 71.526 & 1.403 & 6.683 & 71.526 \\
\hline 7 & .903 & 4.299 & 75.825 & & & & & & \\
\hline 8 & .807 & 3.844 & 79.669 & & & & & & \\
\hline 9 & .718 & 3.420 & 83.089 & & & & & & \\
\hline 10 & .621 & 2.956 & 86.045 & & & & & & \\
\hline 11 & .550 & 2.620 & 88.666 & & & & & & \\
\hline 12 & .501 & 2.386 & 91.051 & & & & & & \\
\hline 13 & .455 & 2.167 & 93.218 & & & & & & \\
\hline 14 & .346 & 1.648 & 94.866 & & & & & & \\
\hline 15 & .294 & 1.400 & 96.266 & & & & & & \\
\hline 16 & .243 & 1.159 & 97.425 & & & & & & \\
\hline 17 & .170 & .809 & 98.234 & & & & & & \\
\hline 18 & .150 & .713 & 98.946 & & & & & & \\
\hline 19 & .116 & .554 & 99.501 & & & & & & \\
\hline 20 & .061 & .288 & 99.789 & & & & & & \\
\hline 21 & .044 & .211 & 100.000 & & & & & & \\
\hline
\end{tabular}

Sumber: Data primer yang diolah peneliti tahun 2016 
Langkah analisis faktor ini menggunakan model Principal Component Analysis (PCA) yang merupakan teknik pemisahan dan ekstraksi faktor (pembobotan faktor) dari analisis faktor. Banyaknya faktor yang masuk dalam model didasarkan pada nilai Eigenvalue yang besarnya lebih besar atau sama dengan 1 (satu). Dengan kriteria tersebut diperoleh 6 (enam) faktor yang teridentifikasi. Hasil perhitungan pada tabel extraction sum of squared loading adalah perincian faktor, eigenvalue lebih besar atau sama dengan satu, persentase varians setiap faktor, dan persentase kumulatif varians yang menjelaskan proporsi atau sumbangan yang diberikan oleh faktor terbentuk tahap penelitian ini. Terdapat 6 (enam) faktor yang terpilih dan memberikan sumbangan sebesar 71,526 persen kumulatif varians. Dengan kata lain, 6 (enam) faktor tersebut dapat menjelaskan variabel-variabel yang mempengaruhi konsumen pria dalam membeli jasa perawatan wajah di Larissa Aesthetic Center Semarang.

\section{Rotated Component Matrix}

Berikut ini adalah tabel yang berisikan hasil dari rotasi faktor

Tabel 14

Rotated Component Matrix

\begin{tabular}{|l|r|r|r|r|r|r|}
\hline & \multicolumn{7}{|c|}{ Component } \\
\cline { 2 - 7 } & \multicolumn{1}{|c|}{$\mathbf{1}$} & \multicolumn{1}{c|}{$\mathbf{2}$} & \multicolumn{1}{c|}{$\mathbf{3}$} & \multicolumn{1}{c|}{$\mathbf{4}$} & \multicolumn{1}{c|}{$\mathbf{5}$} & \multicolumn{1}{c|}{} \\
\hline Dokter spesialis kulit (X15) & .928 & -.021 & .178 & -.125 & .025 & .019 \\
\hline Free Konsultasi dokter (X16) & .924 & -.097 & .209 & -.002 & -.007 & .094 \\
\hline Beauty therapis (X14) & .914 & -.089 & .179 & -.100 & .082 & .008 \\
\hline Potongan harga (X6) & .801 & .150 & -.039 & .288 & .089 & .054 \\
\hline Pemberian hadiah (X11) & .793 & .121 & -.040 & .346 & .144 & .091 \\
\hline Variasi produk (X1) & -.721 & .323 & .364 & -.114 & .054 & -.034 \\
\hline Alat modern (X12) & .637 & -.032 & .327 & .460 & -.018 & -.048 \\
\hline Mempercantik diri (X21) & -.532 & .267 & -.125 & .384 & -.075 & -.098 \\
\hline Harga terjangkau (X4) & -.510 & .418 & .303 & -.183 & -.110 & -.229 \\
\hline Pembayaran mudah (X5) & -.036 & .796 & -.122 & .058 & .022 & -.156 \\
\hline Tempat strategis (X7) & -.072 & .773 & .128 & .094 & -.120 & .168 \\
\hline Lokasi ditengah kota (X8) & -.024 & .739 & -.060 & .098 & .463 & .142 \\
\hline Kemasannya menarik (X2) & -.347 & .380 & -.351 & .326 & .285 & -.046 \\
\hline Ruang tunggu nyaman (X10) & .134 & -.217 & .674 & .048 & -.111 & .030 \\
\hline Referensi teman (X20) & -.031 & .057 & .633 & .014 & .165 & .154 \\
\hline Pelayanan ramah (X13) & .312 & .221 & .625 & -.112 & -.012 & .315 \\
\hline
\end{tabular}


JEMAP : Jurnal Ekonomi, Manajemen, Akuntansi dan Perpajakan

\begin{tabular}{|l|r|r|r|r|r|r|}
\hline \multirow{2}{*}{} & \multicolumn{7}{|c|}{ Component } \\
\cline { 2 - 7 } & \multicolumn{1}{c|}{$\mathbf{1}$} & \multicolumn{1}{c|}{$\mathbf{2}$} & \multicolumn{1}{c|}{$\mathbf{3}$} & \multicolumn{1}{c|}{$\mathbf{4}$} & \multicolumn{1}{c|}{$\mathbf{5}$} & \multicolumn{1}{c|}{$\mathbf{6}$} \\
\hline Member card (X18) & .217 & .105 & .003 & .842 & .055 & -.025 \\
\hline Kualitas produk (X3) & .015 & .228 & .292 & -.061 & .796 & -.108 \\
\hline Lahan parkir luas (X9) & .278 & -.204 & -.243 & .132 & .647 & .138 \\
\hline Testimoni (X19) & -.006 & -.102 & .302 & .060 & -.048 & .843 \\
\hline Pelayanan cepat (X17) & .292 & .406 & .075 & -.266 & .143 & .614 \\
\hline
\end{tabular}

Extraction Method: Principal Component Analysis.

Rotation Method: Varimax with Kaiser Normalization.

a. Rotation converged in 8 iterations.

\section{Menamakan Faktor}

Berikut ini adalah tabel yang berisikan pengelompokkan variabel dalam penelitian ini kedalam faktor-faktor:

\section{Tabel 15}

Penamaan Faktor yang Terbentuk

\begin{tabular}{|c|c|c|c|c|}
\hline $\begin{array}{c}\text { Variabel-variabel yang } \\
\text { membentuk faktor }\end{array}$ & Loading & Component & Nama faktor & $\begin{array}{l}\text { Presentage } \\
\text { of Variance }\end{array}$ \\
\hline $\begin{array}{l}\text { Dokter Spesialis Kulit } \\
\text { Konsultasi Dokter } \\
\text { Beauty Therapis } \\
\text { Potongan Harga } \\
\text { Memberikan Hadiah } \\
\text { Alat Modern }\end{array}$ & $\begin{array}{l}0,928(\mathrm{X} 15) \\
0,924(\mathrm{X} 16) \\
0,914(\mathrm{X} 14) \\
0,801(\mathrm{X} 6) \\
0,793(\mathrm{X} 11) \\
0,637(\mathrm{X} 12)\end{array}$ & Faktor 1 & $\begin{array}{c}\text { Faktor dokter ahli dan } \\
\text { promosi harga }\end{array}$ & 29.404 \\
\hline $\begin{array}{l}\text { Pembayaran Mudah } \\
\text { Tempat Strategis } \\
\text { Lokasi ditengah kota } \\
\text { Harga Terjangkau } \\
\text { Kemasan Menarik }\end{array}$ & \begin{tabular}{|l}
$0,796(\mathrm{X} 5)$ \\
$0,773(\mathrm{X} 7)$ \\
$0,739(\mathrm{X} 8)$ \\
$0,418(\mathrm{X} 4)$ \\
$0,380(\mathrm{X} 2)$ \\
\end{tabular} & Faktor 2 & $\begin{array}{c}\text { Faktor kemudahan } \\
\text { akses }\end{array}$ & 14.232 \\
\hline $\begin{array}{l}\text { Ruang Tunggu nyaman } \\
\text { Referensi Teman } \\
\text { Pelayanan ramah } \\
\text { Variasi Layanan } \\
\end{array}$ & $\begin{array}{l}0,674(\mathrm{X} 10) \\
0,633(\mathrm{X} 20) \\
0,625(\mathrm{X} 13) \\
0,634(\mathrm{X} 21) \\
\end{array}$ & Faktor 3 & $\begin{array}{l}\text { Faktor kualitas } \\
\text { fasilitas }\end{array}$ & 11.312 \\
\hline Member card & 0,842 (X18) & Faktor 4 & $\begin{array}{c}\text { Faktor keanggotaan } \\
\text { Larissa Aesthetic } \\
\text { Center }\end{array}$ & 6.225 \\
\hline $\begin{array}{l}\text { Kualitas produk } \\
\text { Lahan parkir luas } \\
\end{array}$ & $\begin{array}{l}0,796(\text { X3) } \\
0,647(\text { X9) } \\
\end{array}$ & Faktor 5 & \begin{tabular}{|c|} 
Faktor kualitas produk \\
dan Lahan Parkir \\
\end{tabular} & 5.400 \\
\hline $\begin{array}{l}\text { Testimoni } \\
\text { Pelayanan Cepat }\end{array}$ & $\begin{array}{l}0,843 \text { (X19) } \\
0,614 \text { (X17) }\end{array}$ & Faktor 6 & $\begin{array}{c}\text { Faktor testimony dan } \\
\text { pelayanan cepat }\end{array}$ & 4.953 \\
\hline
\end{tabular}

Sumber: data yang diolah peneliti tahun 2016 


\section{KESIMPULAN}

Berdasarkan hasil analisis tentang faktor-faktor yang mempengaruhi konsumen pria dalam membeli jasa perawatan wajah di Larissa Aesthetic Center Semarang, maka dapat diambil kesimpulan sebagai berikut : hasil penelitian mengenai tanggapan responden menunjukkan bahwa sebagian besar responden memiliki persepsi bahwa pria juga membutuhkan perawatan wajah guna untuk menunjang penampilan mereka.

Hasil pengujian analisis faktor diperoleh 6 (enam) faktor yang diidentifikasi dapat mempengaruhi konsumen pria dalam membeli jasa perawatan wajah di Larissa Aesthetic Center Semarang, yaitu Faktor pertama adalah faktor dokter ahli dan promosi harga dengan presentase varians 29,404\% dari nilai eigenvalues sebesar 6,175; Faktor kedua adalah faktor kemudahan akses dengan presentase varians 14,232\% dari nilai eigenvalues sebesar 2,989; Faktor ketiga adalah faktor kualitas pelayanan dengan presentase varians $11,312 \%$ dari nilai eigenvalues 2,375; Faktor keempat adalah Faktor keanggotaan Larissa Aesthetic Center dengan presentase 6,225\% dari nilai eigenvalues 1,307; Faktor kelima adalah faktor kualitas dan Lahan parkir dengan presentase 5,400\% dari nilai eigenvalues 1,134; Faktor keenam adalah faktor pelayanan dan testimony konsumen dengan presentase 4,953\% dari nilai eigenvalues 1,040.

\section{SARAN}

Berdasarkan hasil penelitian, maka berikut ini adalah beberapa saran yang dapat diberikan: hasil penelitian ini diharapkan Larissa Aesthetic Center Semarang dapat mengembangkan teknologi untuk perawatan agar konsumen merasa aman dan percaya bahwa mereka tidak salah memilih tempat perawatan wajah, agar meningkatkan mutu dalam menjalin hubungan dengan konsumen dengan menyedikan member card yang inovatif sehingga dapat membedakan mutu dengan pesaing, memperluas lahan parkir. 


\section{DAFTAR PUSTAKA}

Afifah, Rosi Nur. 2014. Analisis Pengaruh Kualitas Produk, Kualitas Pelayanan, dan Promosi Terhadap Kepuasan Konsumen Untuk Meningkatkan Loyalitas Pelanggan (Skripsi). Semarang: Universitas Diponegoro.

Amanda Ayu Danny. 2016. Analisis Faktor Pengusaha Kuliner Menggunakan Jasa Iklan Instagram “Jakul Semarang” Sebagai Endorser. Semarang (Skripsi): Unika SOEGIJAPRANATA.

Azwar,Saifuddin, 2000. Reliabilitas dan Validitas. Yogyakarta: Pustaka Pelajar.

Didin Dwi Kartikasari. 2014. Studi Fenomenologi Pemaknaan Kecantikan Pada Konsumen Perempuan di Klinik Kecantikan Natasha Skin Care Kota Madiun (Skripsi). Malang: Universitas BRAWIJAYA

Engel, James F, et.al. 1994. Consumer Behavior, Jilid 1. Jakarta: Erlangga.

Kotler, Philip dan Gary Armstrong. 2001. Prinsip-prinsip Pemasaran, Jilid 1, Edisi Kesembilan. Jakarta: Erlangga.

Nenny Silvana ( kompasiana.com: 2011 ).

Santoso, S., F. Tjiptono. (2001). Riset Pemasaran: Konsep dan Aplikasi dengan SPSS. Jakarta: PT Elex Media Komputindo.

Sugiyono. 2010. Metode Penelitian Pendidikan (Pendekatan Kualitatif, Kuantitatif , dan $R \& D)$. Bandung : Alfabeta.

Swastha,Basu. 2001. Manajemen Penjualan. Yogyakarta : BPFE.

Tjiptono, F. (2008). Strategi Bisnis dan Manajemen. Yogyakarta: And.

Vidya Hanesty Purbani. 2013. Analisis Pengaruh Persepsi Harga,Kualitas Produk, Diferensiasi Produk, Kualitas Layanan dan Promosi terhadap keputusan pembelian. Semarang (Skripsi): Universitas DIPONEGORO.

(www.larissa.co.id). 